\title{
Endoscopic treatment of acquired subglottic stenosis in children: Predictors of success
}

\author{
Giselle Cuestas, M.D.,' Verónica Rodríguez, M.D., ${ }^{a}$ Flavia Doormann, M.D.,, Patricio Bellia Munzón, M.D., \\ and Gastón Bellia Munzón, M.D. ${ }^{b}$
}

\begin{abstract}
Subglottic stenosis is a congenital or acquired disease characterized by the narrowing of the airways, from the vocal cords to the lower border of the cricoid cartilage. It is one of the main causes of stridor and respiratory distress in children. More than $90 \%$ of laryngeal stenoses are acquired due to prolonged endotracheal intubation. The pediatric management of subglottic stenosis is complex and may be affected by different factors that have an impact on the final outcome. Treatment may involve endoscopic procedures and/or open surgeries. Here we describe our experience in 35 patients with acquired subglottic stenosis who underwent endoscopic treatment with rigid dilation and identify the potential predictors of success of this technique.

Key words: subglottic stenosis, child, dilation.
\end{abstract}

http:/ / dx.doi.org/10.5546/ aap.2018.eng.422

To cite: Cuestas G, Rodríguez V, Doormann F, Bellia Munzón P, e al. Endoscopic treatment of acquired subglottic stenosis in children: Predictors of success. Arch Argent Pediatr 2018;116(6):422-425.

\section{INTRODUCTION}

Stenosis is a common cause of laryngeal obstruction in pediatric patients. ${ }^{1}$ The subglottis is the most affected region because it is the narrowest part of a child's airway. ${ }^{2}$

Acquired subglottic stenosis (SGS) is, mainly, the consequence of prolonged intubation, with a documented incidence of $1-8 \% .{ }^{3}$ Other risk factors for the development of stenosis are inadequate sedation, the size of the endotracheal tube, a traumatic intubation, an infection during the intubation period, and gastroesophageal reflux.,4-6

a. Unit of Respiratory Endoscopy, Ear, Nose and Throat Department.

b. Surgery Service.

Hospital General de Niños "Dr. Pedro de Elizalde."

Autonomous City of Buenos Aires, Buenos Aires, Argentina.

E-mail address:

Giselle Cuestas, M.D.: giselle_cuestas@yahoo.com.ar

Funding: None.

Conflict of interest: None.

Received: 2-17-2018

Accepted: 6-26-2018
Typically, management strategies are determined by the severity of obstruction in the subglottic lumen; the Cotton-Myer grading system is the classification most commonly used to this end: grade $1,<50 \%$ obstruction; grade 2 , $51-70 \%$ obstruction; grade $3,71-99 \%$ obstruction; and grade 4 , complete luminal obstruction..$^{2,7}$

In general, mild stenoses (grades 1 and 2) are managed without surgery. In the past, the most severe grades were treated with a tracheostomy or an open surgery. At present, an increasingly higher number of events are effectively managed with endoscopic procedures. ${ }^{3}$ Other factors, besides SGS grade, may have an impact on therapeutic outcomes. ${ }^{8}$

Endoscopic dilation is an interesting option for the treatment of SGS because it has shown a lower morbidity compared to open surgery. Here we describe our experience in the treatment of acquired SGS with rigid dilation and identify potential predictors of success of this technique.

\section{MATERIAL AND METHOD}

All patients with SGS treated with rigid dilation at the Unit of Respiratory Endoscopy between November 2001 and November 2017 were assessed retrospectively.

Analyzed outcome measures included cause, stenosis type and grade, comorbidities, age at the time of treatment, and number and frequency of dilations.

"Acute stenosis" was defined when the period between extubation or tracheostomy due to extubation failure and dilation was up to 30 days, whereas "chronic stenosis" was used if it was more than 30 days.

Treatment was considered successful if tracheostomy and/or open surgery were avoided, the patient was decannulated and/or did not have signs or symptoms of respiratory distress, even with residual SGS.

In all patients, rigid dilation was the primary treatment of stenosis. Dilations were done under general anesthesia with increasing diameter endotracheal tubes, depending on the patient's age. Dilation was started with Silastic (a portmanteau of "silicone" and "plastic") bougies 
when stenosis prevented the introduction of a 2.5$\mathrm{mm}$ endotracheal tube. Images were documented (Figures 1 and 2).

All patients were treated with anti-reflux drugs (lansoprazole) for 6 months after dilation. Clinical controls were done weekly in the first month, every 15 days in the second and third months, and then at 6 and 12 months, and parents were welcome to the hospital at any time in case of any problem. A new endoscopic dilation was done if the patient had stridor and dyspnea due to a recurrent injury.

Predictors of success were assessed by means of a statistical analysis using the Fisher's exact test and the Mann-Whitney U test, with a significance level of 0.05 .

The present study was approved by the Hospital Ethics Committee.

\section{RESULTS}

A total of 35 patients were included. Patients' characteristics and analyzed outcome measures are summarized in Table 1.

In all cases, the cause of SGS was mechanical ventilatory support, and the average days with endotracheal intubation was 15.8 (range: 4 days to 3 months).

Age at the time of endoscopic treatment ranged from 1 month to 14 years old. Thirtyfour patients were younger than 5 years. Twelve patients had comorbidities, including heart disease (n: 4), Down syndrome (n: 3), diabetes (n: 1), gastroesophageal reflux (n: 2), tracheal extension (n: 1), and pulmonary disease (n: 6). None of the patients showed glottic involvement. Only 1 patient had a tracheostomy prior to endoscopic treatment.

The number of dilations ranged from 1 to 5 , with a mean of 2.08 dilations per patient. The mean time between dilations was 3 weeks (range: 8 to 38 days) (Figure 3). In 12 cases, adjuvant treatment was administered locally; it included gentamicin and betamethasone (n: 5), mitomycin $\mathrm{C}$ at a dosage of $2 \mathrm{mg} / \mathrm{mL}$ (n: 5) or both (n: 2). No procedural complications were observed.

The overall success rate was $88.6 \%: 96.4 \%$ in acute SGSs and $57.1 \%$ in chronic SGSs.

In 29 patients, it was possible to avoid a tracheostomy. Decannulation was done in the patient who already had undergone a tracheostomy. One patient required a temporary tracheostomy after dilation due to his pulmonary disease and was decannulated 6 years after without airway treatment requirement.

Endoscopic treatment failed in 4 patients $(11.4 \%)$. A tracheostomy was done in 2 of them and a cricotracheal resection in one surgical time, in the other 2.

Follow-up lasted a mean of 1 year (range: 3 months to 6 years).

FIGURE 1. A and B. Post-intubation subglottic stenosis, grade 2 (A) and grade 3 (B) according to the Cotton-Myer classification

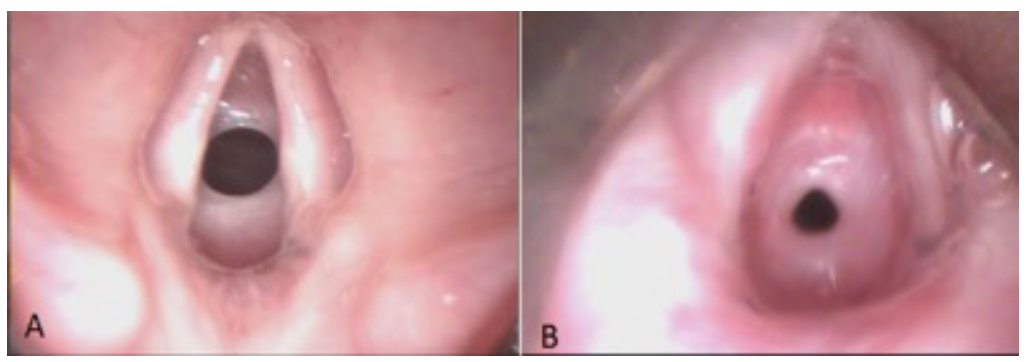

FIgURE 2. A. Grade 3 subglottic stenosis. B. Dilation with endotracheal tube. C. Endoscopic image after dilation showing an adequate subglottis diameter

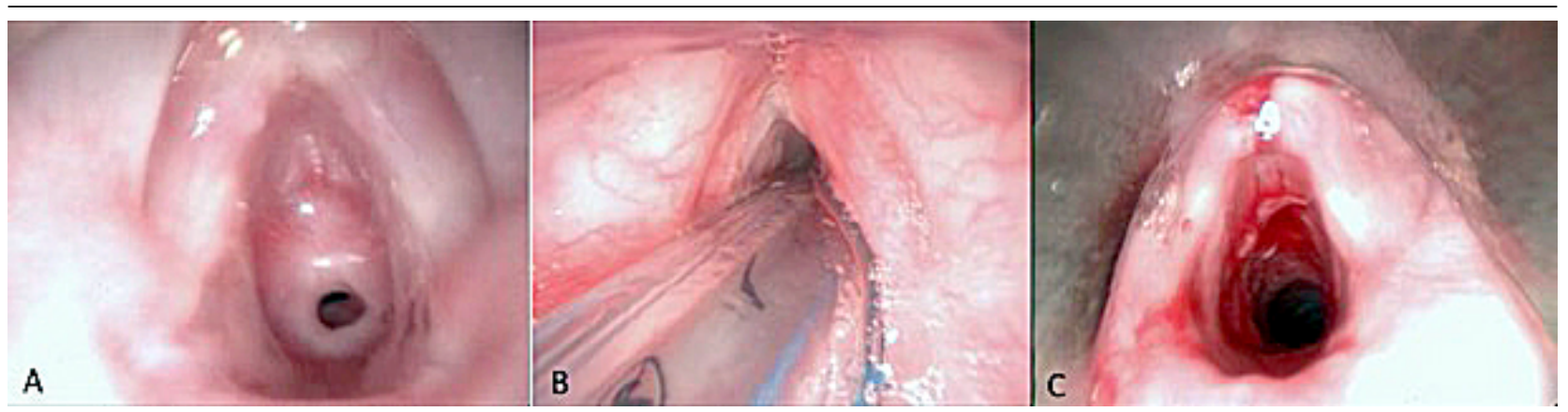




\section{DISCUSSION}

Approximately $90 \%$ of children have postintubation acute injuries, but most of these are mild and improve few days after extubation. ${ }^{9}$ Sometimes injuries are moderate to severe and may progress to scarring sequelae in the larynx that may affect the quality of life by causing dysphonia or dyspnea.

The first sign of stenosis may be extubation failure, the need for reintubation with a smaller endotracheal tube, exercise intolerance, stridor or persistent dysphonia after extubation. A plain cervical spine X-ray may be useful for diagnosis.

Unlike congenital cases of SGS, which may improve with growth, acquired SGS does not improve over time. ${ }^{2}$
A wide variety of surgical and endoscopic techniques have been developed for the management of acquired SGS in children. ${ }^{2,7}$ The main objective of treatment is to avoid tracheostomy or allow decannulation. In a child with SGS, the risk for death due to the cannula (caused by obstruction or accidental decannulation) is $1-2 \%$ per year. ${ }^{2}$

Endoscopic techniques are an alternative to open surgery; the main therapeutic option is dilation. ${ }^{3,10}$

Dilation is not recommended in cases of congenital stenosis and airway structural alterations (cartilaginous involvement). ${ }^{1,2}$

There seems to be a relation between the time of progression and the success of endoscopic

Table 1. Characteristics of patients with subglottic stenosis managed with rigid dilation

\begin{tabular}{|c|c|c|c|c|}
\hline & & $\begin{array}{l}\text { Successful treatment } \\
\text { (n: 31) }\end{array}$ & $\begin{array}{l}\text { Unsuccessful treatment } \\
\text { (n: } 4)\end{array}$ & $\begin{array}{l}\text { Total number of patients } \\
\text { (n: } 35)\end{array}$ \\
\hline Sex & Male & $17 \mathrm{p}$ & $3 p$ & $20 \mathrm{p}$ \\
\hline $\begin{array}{l}\text { Mean age at the time } \\
\text { of treatment }\end{array}$ & & 10.6 months & 5 years & 1.4 years \\
\hline Stenosis type $\mathrm{e}^{* *}$ & $\begin{array}{l}\text { Acute } \\
\text { Chronic }\end{array}$ & $\begin{array}{l}27 \mathrm{p} \\
4 \mathrm{p}\end{array}$ & $\begin{array}{l}1 p \\
3 p\end{array}$ & $\begin{array}{l}28 \mathrm{p} \\
7 \mathrm{p}\end{array}$ \\
\hline Stenosis grade & $\begin{array}{l}\text { Grade } 2 \\
\text { Grade } 3\end{array}$ & $\begin{array}{l}13 \mathrm{p} \\
18 \mathrm{p}\end{array}$ & $\begin{array}{l}1 p \\
3 p\end{array}$ & $\begin{array}{l}14 \mathrm{p} \\
21 \mathrm{p}\end{array}$ \\
\hline Comorbidities & & $10 \mathrm{p}$ & $2 \mathrm{p}$ & $12 \mathrm{p}$ \\
\hline Adjuvant treatment & & $10 \mathrm{p}$ & $2 \mathrm{p}$ & $12 \mathrm{p}$ \\
\hline
\end{tabular}

* For the statistical analysis of age distribution in the success and failure groups, the Mann-Whitney U test was used, and the difference was not significant $(p=0.06)$.

${ }^{* *}$ For the statistical analysis of results in acute and chronic stenoses, the Fisher's exact test was used, and the difference of success between acute and chronic stenoses was significant $(\mathrm{p}=0.02)$.

FIGURE 3. Number of dilations per patient. Success: patients who responded to endoscopic treatment and did not require another dilation. Failure: patients who did not achieve an adequate diameter with the dilation and who required a tracheostomy or an open surgery

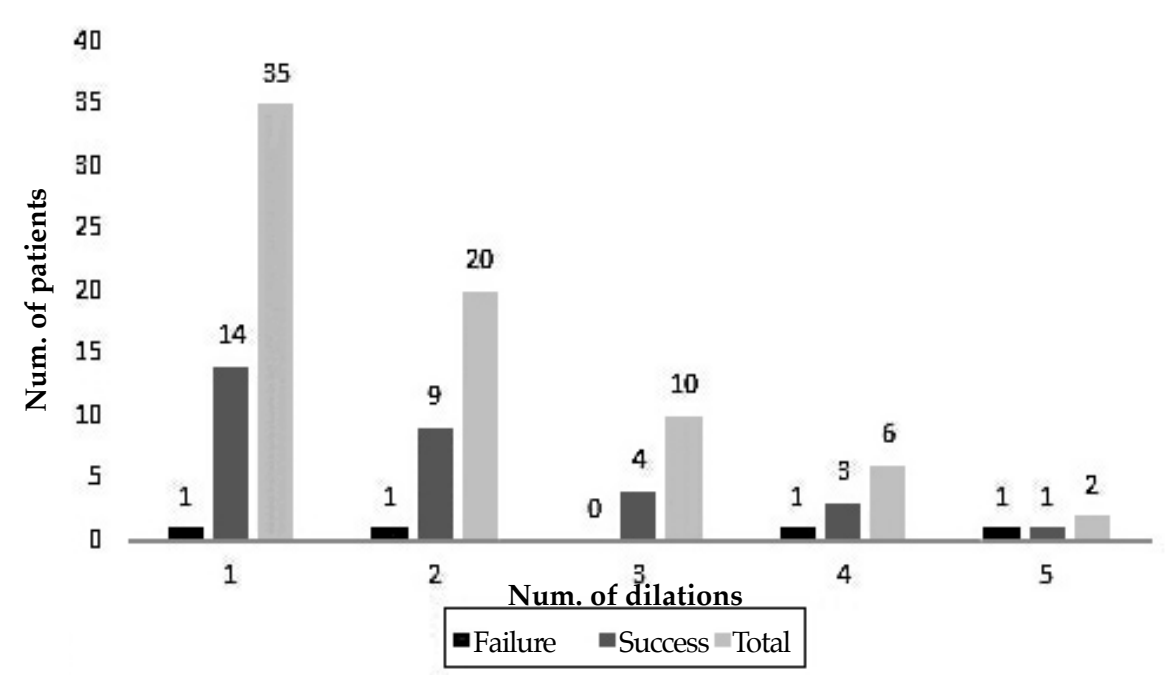


treatment, associated with the characteristics of scarring. ${ }^{11}$ A greater possibility of a favorable response in narrow, laminar, and soft stenoses has been documented, consistent with immature scar tissue. ${ }^{11,12}$ On the contrary, children with longstanding stenosis with mature, firm, and thick scar tissue have a lower response likelihood. .,11-13 $^{-1}$

In our series, patients with acute stenosis had a better response compared to chronic cases, regardless of the stenosis grade. The most commonly used SGS grades would not be useful for the management of acute SGS.

Involvement in multiple levels increases the possibility of failure; one of our patients who had tracheal involvement required open surgery. ${ }^{2}$

Some authors state that dilation is limited in patients with comorbidities or severe stenosis.,10,13,14 Other authors have referred greater success likelihood in younger children, patients with milder stenoses, and in the absence of a prior tracheostomy. ${ }^{11,12}$

Although the number of cases in our series was limited, the predictor of success of rigid dilation was acute stenosis. No differences were observed in results in terms of the stenosis grade and the presence of comorbidities. In our opinion, dilation at a younger age increases the probability of a favorable result; however, the statistical analysis of age distribution in the success and failure groups showed that the difference was not significant.

Dilation may be done with endotracheal tubes or bougies (rigid dilation) and, at present, balloon dilation is gaining ground. ${ }^{7,11,13,15}$

There are no studies comparing rigid dilation to balloon dilation, so it is not possible to determine if one method is better than the other. ${ }^{13}$ However, unlike the shear stress of rigid dilators, the balloon exerts a radial pressure on the stenosis (that may be measured and controlled), which may cause tissue damage and, as a result, a lower scarring. ${ }^{2,10,11,15}$ The main disadvantage of this method is its cost.

Complications are not frequent. Tracheitis, mucous membrane laceration, pneumomediastinum, and even death have been documented. ${ }^{10,14}$

Endoscopic dilation entails risks that include worsened stenosis, unplanned surgical intervention, and a delay in definite management. ${ }^{10}$ Based on our experience, a maximum of 5 dilations per patient is recommended and a new dilation should only be done if an adequate subglottic diameter is not achieved with the previous dilation.

Endoscopic dilation may be considered the first line of treatment for acute acquired SGS in children. Although the extent of the result is smaller in chronic cases, complications are not significant and, in the case of failure, future reconstructive surgeries may be done. ${ }^{11}$

\section{Acknowledgments}

We would like to thank Fernando Torres, M.D., for his valuable collaboration with the statistical analysis of results.

\section{REFERENCES}

1. Chen $\mathrm{C}, \mathrm{Ni} \mathrm{WH}$, Tian $\mathrm{TL}, \mathrm{Xu} \mathrm{ZM}$. The outcomes of endoscopic management in young children with subglottic stenosis. Int J Pediatr Otorhinolaryngol. 2017; 99:141-5.

2. Jefferson ND, Cohen AP, Rutter MJ. Subglottic Stenosis. Semin Pediatr Surg. 2016; 25(3):138-43.

3. Talwar R, Virk JS, Bajaj Y. Paediatric subglottic stenosis Have things changed? Our experience from a developing tertiary referral centre. Int J Pediatr Otorhinolaryngol. 2015; 79(12):2020-2.

4. Schweiger C, Manica D, Pereira DR, et al. Undersedation is a risk factor for the development of subglottic stenosis in intubated children. J Pediatr (Rio J). 2017; 93(4): 351-5.

5. Manica D, Schweiger C, Maróstica PJ, et al. Association between length of intubation and subglottic stenosis in children. Laryngoscope. 2013; 123(4):1049-54.

6. Mesallam TA. Oropharyngeal 24-hour $\mathrm{pH}$ monitoring in children with airway-related problems. Clin Exp Otorhinolaryngol. 2016; 9(2):168-72.

7. Bitar MA, Al Barazi R, Barakeh R. Airway reconstruction: review of an approach to theadvanced-stagelaryngotracheal stenosis. Braz J Otorhinolaryngol. 2017; 83(3):299-312.

8. Monnier P. Acquired post-intubation and tracheostomyrelated stenoses. In: Monnier P (ed). Pediatric Airway Surgery: Management of laryngotracheal stenosis in infants and children. Lausanne, Switzerland: Springer; 2011.Págs.183-98.

9. DeLima Eda S, de Oliveira MA, Barone CR, et al. Incidence and endoscopic characteristics of acute laryngeal lesions in children undergoing endotracheal intubation. Braz J Otorhinolaryngol. 2016; 82(5):507-11.

10. Maresh A, Preciado D, O'Connell A, Zalzal GH. A comparative analysis of open surgery vsendoscopic balloon dilation for pediatric subglottic stenosis. JAMAOtolaryngol Head Neck Surg. 2014; 140(10):901-5.

11. Maunsell R, Avelino M. Balloon laryngoplasty for acquired subglotticstenosisin children: predictive factors for success. Braz J Otorhinolaryngol. 2014; 80(5):409-15.

12. Avelino M, Maunsell R, JubéWastowski I. Predicting outcomes of balloon laryngoplasty in children with subglottic stenosis. Int J Pediatr Otorhinolaryngol. 2015; 79(4):532-6.

13. Chueng K, Chadha NK. Primary dilatation as a treatment for pediatric laryngotracheal stenosis: Asystematic review. Int J Pediatr Otorhinolaryngol. 2013; 77(5):623-8.

14. Lang M, BrietzkeSE. Asystematic review and meta-analysis of endoscopic balloon dilation of pediatric subglottic stenosis. Otolaryngol Head Neck Surg. 2014; 150(2):174-9.

15. Filiz A, UlualpSO. Long-term outcomes of balloon dilation for acquired subglottic stenosis in children. Case Rep Otolaryngol. 2014; 2014:304593. 